edges of the atriotomy, and the valve replacement was completed. After right atrial closure, the balloons were deflated, and the catheters were withdrawn. The operation was concluded in the standard fashion.

\section{DISCUSSION}

In our center a small right thoracotomy on the beating heart is the preferred technique for patients undergoing redo operations requiring a tricuspid or mitral valve operation. Excellent exposure is crucial for a successful valve procedure, particularly when the operation is conducted through small incisions. In addition, this approach offers a good exposure to the atrial valves and minimizes the mediastinal dissection, playing a key role in reduction of blood loss and cardiac injuries. ${ }^{4}$

The use of vacuuming without caval occlusion allows a bloodless surgical field; however, air aspiration on venous drainage can cause some problems in the extracorporeal circulation. Our technique of caval occlusion represents a useful alternative in reoperative surgical intervention. Although we have now used this approach only twice, we strongly believe that it is attractive for several reasons. First of all, it reduces mediastinal dissection and the relative risk of injuries to the great vessels. Moreover, it allows a bloodless working environment. Last, but not least, the technique is safe and easy to perform. We think that it should be kept in the armamentarium of the cardiothoracic surgeon and should be considered in all reoperative operations performed with minithoracotomies.

\section{References}

1. Unsworth-White MJ, Herriot A, Valencia O, Poloniecki J, Smith EE, Murday AJ, et al. Resternotomy for bleeding after cardiac operation: a marker for increased morbidity and mortality. Ann Thorac Surg. 1995;59:664-7.

2. Seeburger J, Borger MA, Falk V, Kuntze T, Czesla M, Walther T, et al. Minimal invasive mitral valve repair for mitral regurgitation: results of 1339 consecutive patients. Eur J Cardiothorac Surg. 2008;34:760-5.

3. Lee TC, Desai B, Glower DD. Results of 141 consecutive minimally invasive tricuspid valve operations: an 11-year experience. Ann Thorac Surg. 2009;88: 1845-50.

4. Modi P, Hassan A, Chitwood WR Jr. Minimally invasive mitral valve surgery: a systematic review and meta-analysis. Eur J Cardiothorac Surg. 2008;34:943-52.

\title{
Axillary cannulation for endo-occlusion and antegrade flow during complex reoperative mitral valve surgery
}

\author{
Robert Saeid Farivar, MD, PhD, ${ }^{\mathrm{a}}$ Seth Lowy, BS, ${ }^{\mathrm{b}}$ and Joss Fernandez, MD, ${ }^{\mathrm{a}}$ Iowa City, Iowa, and Irvine, \\ Calif
}

A 54-year-old man had severe paravalvular leak 10 years after a second mitral valve replacement and third mitral valve operation. As a child, the patient had a congenital partial atrioventricular canal defect. He underwent patch repair of the septum secundum atrial septal defect and had a cleft mitral repair at age 16 years. This repair was durable until the age of 28 years, when he required mitral valve replacement with a 31-mm Björk-Shiley mechanical valve (Shiley, Inc, Irvine, Calif) for severe mitral regurgitation. At 44 years of age, although this valve was functioning well, he had it replaced owing to failure risk. The patient underwent mitral valve re-replacement with a $29-\mathrm{mm}$ CarboMedics valve (Sulzer

From University of Iowa Hospitals and Clinics, ${ }^{\text {a }}$ Iowa City, Iowa; and Edwards Lifesciences LLC, ${ }^{\mathrm{b}}$ Irvine, Calif.

Disclosures: Dr Farivar has been a consultant for Edwards Lifesciences.

Received for publication Oct 19, 2010; accepted for publication Nov 5, 2010; available ahead of print Jan 27, 2011.

Address for reprints: Robert Saeid Farivar, MD, PhD, University of Iowa Hospitals and Clinics, 200 Hawkins Dr SE 517GH, Iowa City, IA 52242 (E-mail: robert-farivar@uiowa.edu).

J Thorac Cardiovasc Surg 2010;142:462-4

0022-5223/\$0.00

Published by Elsevier Inc. on behalf of The American Association for Thoracic Surgery

doi:10.1016/j.jtcvs.2010.11.012
CarboMedics, Inc, Austin, Tex) approximately 10 years ago. During that operation, he had a perioperative stroke and a 1-month hospital stay. Nonetheless, he made a full recovery and now returned for a fourth mitral valve procedure.

During the previous year, symptomatic severe mitral regurgitation had developed. Echocardiography demonstrated mitral regurgitation along a $160^{\circ}$ dehiscence along the previous P1-P2 region. The valve was not "rocking." He had an 8-cm left atrium, normal left ventricular function, along with mild aortic insufficiency and moderate tricuspid regurgitation. Right heart catheterization demonstrated elevated pulmonary pressures $(55 \mathrm{~mm} \mathrm{Hg} / 21 \mathrm{~mm} \mathrm{Hg}$ ) and a mean wedge pressure of $20 \mathrm{~mm} \mathrm{Hg}$. Comorbidities included Childs-Pugh class A cirrhosis owing to longstanding congestive hepatopathy and chronic obstructive pulmonary disease on $2 \mathrm{~L}$ of supplemental oxygen.

Given the hostile mediastinum, the decision was made to approach the mitral valve by a right thoracotomy. Evaluation of the aortoiliac system with computed tomography demonstrated severe disease. As a result, axillary cannulation was chosen for antegrade flow. Given the aortic valve insufficiency, we decided against cold fibrillatory arrest, and the Port Access Minimally Invasive Valve System 

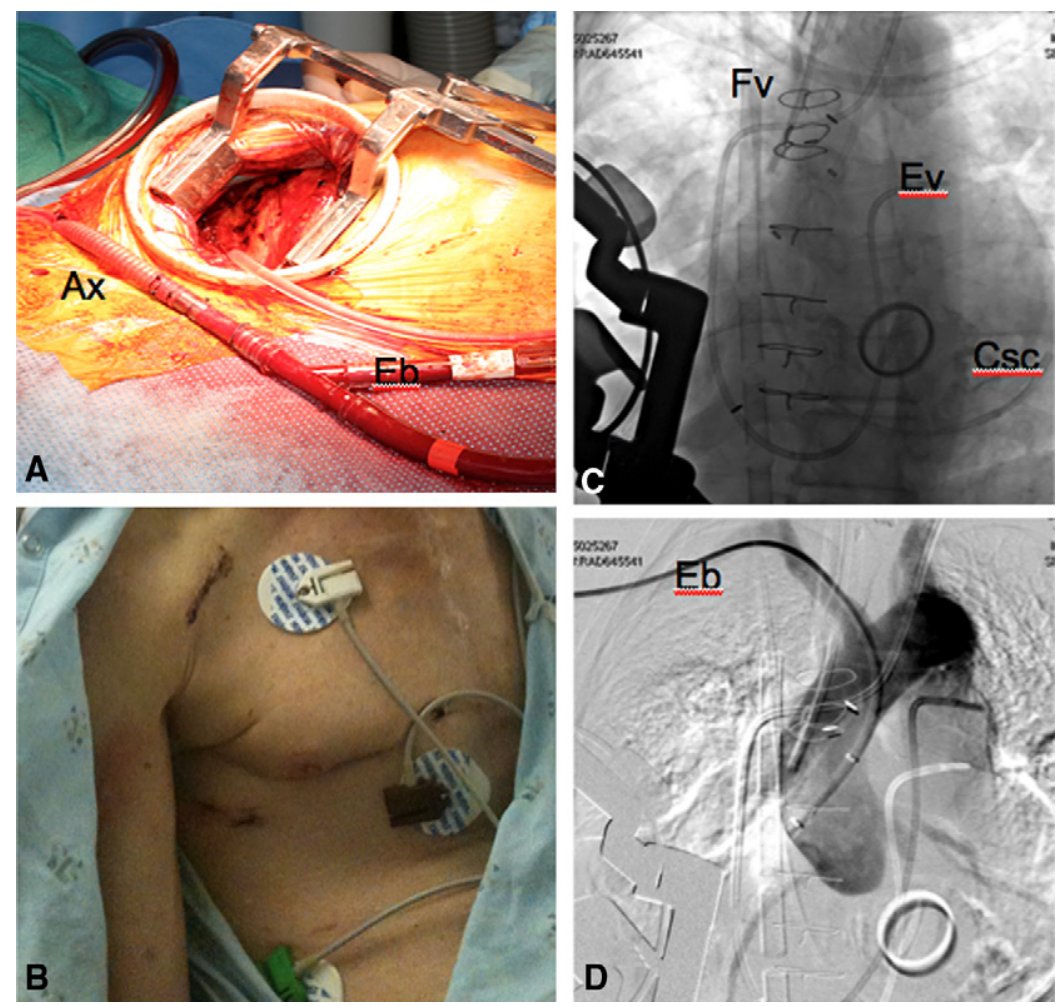

FIGURE 1. A, Right anterolateral thoracotomy in the fourth intercostal space demonstrating an 8-mm Dacron graft $(A x)$ sewn to the axillary artery. The endoballoon $(E b)$ is advanced through the side arm, which is attached to the Dacron graft. The final arm provides arterial inflow. B, Postoperative incision (14 days) documenting the axillary and inframammary and chest tubes incisions. C, Fluoroscopic shot demonstrating the multistage $25 \mathrm{~F}$ femoral venous cannula placed bicavally $(F v)$, the endopulmonary artery vent placed through the right internal jugular vein $(E v)$, the coronary sinus catheter $(C s c)$ placed through the right internal jugular vein as well. D, Angiographic subtracted film demonstrating the endoballoon $(E b)$ placed through the right axillary-innominate arterial system, with the balloon at the sinotubular junction. The aortic valve has good competency and the great vessels are shown.

(Edwards Lifesciences LLC, Irvine, Calif) was used with modifications.

The patient was placed in a gentle right thoracotomy position. Via the right internal jugular vein, an EndoVent catheter (Edwards Lifesciences) was placed in the pulmonary artery, and a coronary sinus catheter was placed for retrograde cardioplegia before incision (Figure 1,C). We exposed the right axillary artery in the deltopectoral groove at the lateral third of the clavicle (Figure 1, A). We administered 5000 units of heparin and then attached an 8-mm Dacron graft as a "chimney" in an end-to-side manner. We then attached a 21-mm endocannula with a Y-arm for an endoballoon and connector for antegrade perfusion (Figure 1, A). We performed a thoracotomy in the right fourth intercostal space in the inframammary crease. After extensive adhesiolysis, we administered systemic heparin and placed a $25 \mathrm{~F}$ femoral venous cannula bicavally with echocardiographic guidance (Figure 1,C).

Using fluoroscopy, we then placed a guidewire through the axillary system abutting the aortic valve (Figure 1,D) at the sinotubular junction. We then administered full bypass in an antegrade manner via the axillary cannula (Figure 1, $D$ ). We were able to achieve a flow rate of $5 \mathrm{~L} / \mathrm{min}$. Using moderate hypothermia and antegrade (through the endoballoon) as well as retrograde (using the coronary sinus catheter) cardioplegia, we arrested the heart and then approached the mitral valve.

We dissected out the Sondergaard groove inasmuch as the patient had a previous transseptal patch from the cleft mitral repair. We inflated the endoballoon to arrest the heart. The previous valve was encountered in a severely enlarged 8 -cm left atrium with an obvious, nearly $180^{\circ}$ dehiscence and fibrin across the valve. The patient underwent routine third time mitral valve replacement with a size 29 tissue valve. Total endoballoon (crossclamp) time was 87 minutes, and bypass time was 160 minutes. He was discharged home on postoperative day 16 in good condition. His recovery was slowed owing to Childs-Pugh A cirrhosis. At 2 months' follow-up, he is in excellent condition, no longer receiving supplemental oxygen at home, and with decreasing furosemide (Lasix) requirement.

\section{DISCUSSION}

Minimally invasive and right chest approaches to the mitral valve have been used for complex reoperative mitral valve surgery as well as routine mitral valve surgery. ${ }^{1}$ They 
offer advantages such as avoidance of a hostile mediastinum with previous coronary bypass grafts and adhesed chambers. In the case of endocannulae and endo-occlusion, they offer the ability to perform the procedure with a single incision on the heart. There are disadvantages, such as the need to dissect out the aorta if a crossclamp is used and retrograde arterial flow if the femoral system is used. Additionally, older data with femoral access and endoballoon occlusion had shown high dissection rates, ${ }^{2}$ although this has not been the case in more modern series of port access surgery. ${ }^{3}$

In our case, because the patient had a previous stroke and multiple previous procedures in a moderately calcified system, we preferred antegrade flow and chose an axillary cannulation strategy. Additionally, inasmuch as we wished to minimize dissection of the aorta from a right chest approach, we chose to place the endoballoon through the axillary chimney. This strategy yielded excellent flows of up to $5 \mathrm{~L} / \mathrm{min}$ when using vacuum-assisted drainage and a $25 \mathrm{~F}$ multilumen femoral venous cannula. Although we could have chosen a cold fibrillatory strategy, the aortic insufficiency and the need to remove a heavily entrenched valve dissuaded us from that method. The combination of antegrade cardioplegia through the aortic root and intermittent retrograde cardioplegia through the coronary sinus, along with moderate $\left(28^{\circ} \mathrm{C}\right)$ hypothermia, provided excellent protection during the right thoracotomy. Separation from bypass was uneventful. Postoperatively, he continues to do well and is pleased with the cosmetic aspect of the scar as well (Figure 1, B).

To our knowledge, this is one of the few reports of axillary cannulation with an endoballoon placed through the axillary cannula. In our hands, it was a reasonable strategy for complex reoperative mitral surgery and may be an interesting method for providing antegrade flow and a single suture line on the heart when performing mitral valve surgery.

\section{References}

1. Casselman FP, La Meir M, Jeanmart H, Mazzarro E, Coddens J, Van Praet F, et al. Endoscopic mitral and tricuspid valve surgery after previous cardiac surgery. Circulation. 2007;116(11 Suppl):I270-5.

2. Mohr FW, Falk V, Diegeler A, Walther T, van Son JA, Autschbach R. Minimally invasive Port-Access mitral valve surgery. J Thorac Cardiovasc Surg. 1998;115: 567-74; discussion, 574-6.

3. Casselman FP, Van Slycke S, Wellens F, De Geest R, Degrieck I, Van Praet F, et al. Mitral valve surgery can now routinely be performed endoscopically. Circulation. 2003;108(Suppl 1):II48-54.

\title{
Total ventricular assist for long-term treatment of heart failure
}

\author{
Antonis A. Pitsis, MD, FETCS, FESC, ${ }^{\mathrm{a}}$ Aikaterini N. Visouli, MD, ${ }^{\mathrm{a}}$ Vlasis Ninios, MD, MRCP, ${ }^{\mathrm{a}}$ and \\ Dimitrios T. Kremastinos, MD, FESC, ${ }^{\mathrm{b}}$ Thessaloniki and Athens, Greece
}

Despite expert opinion that mechanical circulatory support (MCS) should be considered before the sequelae of severe right ventricular (RV) failure, biventricular support is applied in a significant percentage of long-term MCS recipients and is associated with increased mortality compared with mortality after isolated left ventricular (LV) support. ${ }^{1}$

Total artificial heart and biventricular MCS application is closely related to transplant eligibility. ${ }^{2}$ Transplantineligible patients with refractory biventricular failure have no treatment options other than end-of-life care.

\footnotetext{
From the Thessaloniki Heart Institute, ${ }^{\text {a }}$ St Luke's Hospital, Thessaloniki, Greece; and the Second Department of Cardiology, ${ }^{\mathrm{b}}$ Medical School, University of Athens, Attikon Hospital, Athens, Greece.

Disclosures: Authors have nothing to disclose with regard to commercial support. Received for publication July 8, 2010; revisions received Oct 5, 2010; accepted for publication Nov 8, 2010; available ahead of print Jan 31, 2011.

Address for reprints: Antonis A. Pitsis, MD, FETCS, FESC, Thessaloniki Heart Institute, St Luke's Hospital, 552 36, Thessaloniki, Greece (E-mail: apitsis@ otenet.gr). J Thorac Cardiovasc Surg 2011;142:464-7

$0022-5223 / \$ 36.00$

Copyright (c) 2011 by The American Association for Thoracic Surgery doi:10.1016/j.jtcvs.2010.11.014
}

Implantation of newer-generation, long-term, continuousflow left ventricular assist devices (LVADs) has contributed to improved results of MCS. ${ }^{3}$ Long-term, continuous-flow, right ventricular assist devices (RVADs) do not exist, and long-term biventricular support with the new pumps has not been reported.

\section{CLINICAL SUMMARY}

We report the first cases of elective, single-stage, LV and RV support with 2 second-generation axial flow pumps. We applied total ventricular assist (tVA) as long-term treatment to 2 male patients with ischemic and idiopathic end-stage biventricular failure in Interagency Registry for Mechanically Assisted Circulatory Support profiles 2 and 3. The patients were not suitable for transplantation because of advanced age and diabetes mellitus with end-organ damage; the second patient also had fixed pulmonary hypertension, increased pulmonary vascular resistance, and transpulmonary gradient (Table 1). Institutional ethics committee approval and informed consent were obtained in both cases. 